$\mathrm{HbA}(1 \mathrm{c})$ over 1 year in drug-naive patients with type 2 diabetes. Diabet Med 2007;24:955-61.

33 Rosenstock J, Baron MA, Dejager S, Mills D, Schweizer A. Comparison of vildagliptin and rosiglitazone monotherapy in patients with type 2 diabetes: a 24 -week, doubleblind, randomized trial. Diabetes Care 2007;30:217-23.

34 Charbonnel B, Karasik A, Liu J et al. Efficacy and safety of the dipeptidyl peptidase-4 inhibitor sitagliptin added to ongoing metformin therapy in patients with type 2 diabetes inadequately controlled with metformin alone. Diabetes Care 2006;29:2638-43.

35 Aschner P, Kipnes MS, Lunceford JK et al. Effect of the dipeptidyl peptidase-4 inhibitor sitagliptin as monotherapy on glycemic control in patients with type 2 diabetes. Diabetes Care 2006;29:2632-7.

36 Kim D, MacConell L, Zhuang D et al. Effects of once-weekly dosing of a longacting release formulation of exenatide on glucose control and body weight in subjects with type 2 diabetes. Diabetes Care 2007;30:1487-93.

Address for correspondence: Dr JW Stephens, Diabetes Research Group, Institute of Life Sciences, Swansea University, Swansea SA2 8PP. Email: J.W.Stephens@Swansea.ac.uk

\title{
Cardiovascular risk and prevention in diabetes mellitus
}

\section{Aled W Roberts, consultant physician and honorary lecturer, University Hospital of Wales and Wales College of Medicine}

Historically, disease of the cardiovascular system accounts for the death of approximately $70 \%$ of people with diabetes mellitus (DM). ${ }^{1}$ Type 2 DM (T2DM) increases the risk of cardiovascular disease (CVD) 2-4 times. ${ }^{2}$ Type 1 DM (T1DM) also markedly increases the risk of premature CVD. ${ }^{3}$

The pathophysiology of CVD in diabetes is complex and not dependent on the effects of hyperglycaemia alone. In T2DM a constellation of risk factors contribute to the development of early CVD, including hypertension and dyslipidaemia. These result in metabolic changes which, coupled with a sedentary lifestyle, obesity and smoking, enhance the deleterious effects of hyperglycaemia and accelerate atherosclerotic disease in the vasculature. People with T1DM are generally diagnosed at a young age and exposure to hyperglycaemia takes place over a prolonged time period compared with T2DM. CVD in T1DM may relate more closely to the burden of hyperglycaemia and its complications. ${ }^{4}$

Over $90 \%$ of people with DM have T2DM, and the prevalence is accelerating in the developed and developing world. The current prevalence of diabetes in adults in the UK is estimated to be $7.4 \%,{ }^{5}$ though rates may be higher in certain ethnic and patient subgroups. This article considers the pathophysiology of CVD in T2DM, the management of cardiovascular risk in this population and the tools available for assessment of cardiovascular risk in T2DM. A brief summary of the pathophysiology, assessment and management of cardiovascular risk in T1DM will also be provided. People with diabetes benefit from secondary prevention strategies at least as much as those without diabetes. This article focuses on primary prevention of cardiovascular events.

\section{Cardiovascular risk in type 2 diabetes}

\section{Pathophysiology}

The earliest stages in the development of atherosclerosis involve the adhesion and migration of monocytes through the vascular endothelium and into the vascular intima. This may be facilitated by the pro-inflammatory, procoagulant and vasoconstricted state associated with diabetes. Within the intima, monocytes transform into macrophages and take up modified lipoproteins resulting in foam cell formation. Foam cells accumulate within the vascular wall to form a fatty streak. With the recruitment of smooth muscle cells, low-grade chronic inflammation and modulation of the extracellular matrix, the atherosclerotic plaque develops. This comprises a fibrous outer layer in contact with the plasma overlying a procoagulant lipid-rich core. The rupture or erosion of any part of this fibrous cap exposes the procoagulant lipid to the circulating plasma, resulting in platelet activation, thrombosis and an acute vascular event. This atherosclerotic process is accelerated in T2DM (summarised in Fig 1).

Many people with T2DM are also hypertensive ${ }^{6}$ which contributes to the premature development of vascular disease. Diabetes is associated with a typical dyslipidaemia comprising mildly elevated levels of small dense low-density lipoprotein (LDL), reduced levels and altered composition of high-density lipoprotein (HDL) and increased triglyceride-rich lipoprotein particles. Glycated, small dense LDL is associated with increased oxidative stress within the vasculature, while reduced concentrations of altered HDL are less able to participate in atheroprotective functions such as reverse cholesterol transport. 


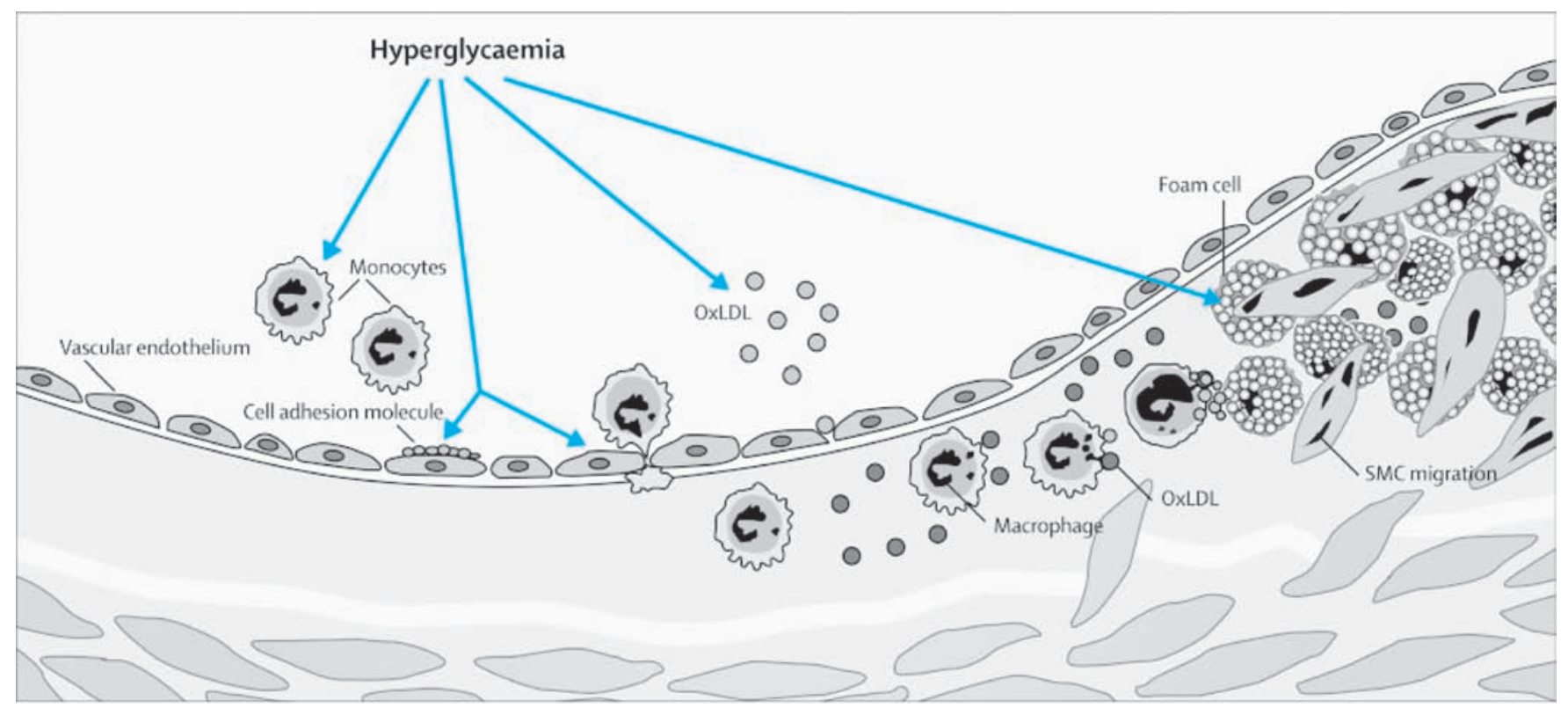

Fig 1. Effects of hyperglycaemia on the atherosclerotic process including cell adhesion molecule expression, monocyte recruitment and migration into the vascular intima, involvement of oxidised low-density lipoprotein (OxLDL), foam cell formation and vascular smooth muscle cell (SMC) migration and proliferation, resulting in fatty streak formation. Adapted from Ref 7.

Insulin resistance is an early and major component of T2DM and an independent risk factor for CVD. ${ }^{8}$ Endothelial dysfunction ${ }^{9}$ and increased carotid intima-media thickness ${ }^{10}$ may be early, reversible features of CVD and can be assessed non-invasively. Thus, early identification of insulin resistance and impaired endothelial function may identify those at particular risk of CVD and enable targeting of aggressive risk factor control to those who will most benefit.

\section{Assessment of cardiovascular risk in type 2 diabetes}

The use of epidemiological data to assess cardiovascular risk is well established. The Framingham risk charts ${ }^{11}$ have been used extensively and may be used to aid consideration for antihypertensive and lipid-lowering therapy in people with diabetes. The UK Prospective Diabetes Study (UKPDS) online risk calculator is recommended in National Institute for Health and Clinical Excellence (NICE)

\section{Key points}

Cardiovascular risk is linearly related to hyperglycaemia in diabetes mellitus (DM)

Reversal of hyperglycaemia using pharmacological agents alone has not been clearly shown to reduce cardiovascular disease (CVD) in type 2 DM (T2DM)

Multiple risk factors contribute to CVD in T1DM and T2DM; effective risk management requires lifestyle interventions, aggressive management of glucose control and other cardiovascular risk factors

Early, assiduous management of glucose control in DM may impart metabolic imprinting which reduces cardiovascular complications in the long term

Randomised controlled trials demonstrate that lipid and blood pressure lowering independently reduce cardiovascular events in T2DM

KEY WORDS: cardiovascular disease, cardiovascular risk, primary prevention, type 1 diabetes, type 2 diabetes guideline CG66. ${ }^{12}$ The QRISK algorithm $^{13}$ may be more applicable to populations in England and Wales as it factors ethnicity and social deprivation into the risk assessment.

\section{Management of cardiovascular risk in type 2 diabetes}

The first step in the management of cardiovascular risk in patients with T2DM should be a structured education programme incorporating dietary advice and an appropriate exercise plan.

\section{Glucose control}

Increasing fasting glucose in $\mathrm{T} 2 \mathrm{DM}$ is related to increased cardiovascular event rates $^{14}$ but the relationship between glucose lowering and CVD risk reduction is complex (Table 1). The UKPDS study group showed a reduction of myocardial infarction rates with metformin monotherapy in a small subgroup of obese individuals. ${ }^{15}$ The putative beneficial effects of metformin on cardiovascular events have made it the first-line therapy for the management of T2DM. However, none of the other glucose lowering agents in monotherapy or in 
combination has been shown in the UKPDS or other clinical studies to significantly reduce major cardiovascular events. Recent meta-analyses have suggested that intensive glucose lowering with multiple glucose lowering therapies reduces major cardiovascular events, but not mortality. ${ }^{16}$ However, a report of 10 year follow-up data from the UKPDS group ${ }^{17}$ suggests that early intensive glucose lowering has a metabolic memory effect - significantly lowering cardiovascular events, but with a considerable time lag over a long time period.

The recent Action to Control Cardiovascular Risk in Diabetes (ACCORD) trial ${ }^{18}$ which targeted intensive glucose control in high-risk individuals with established T2DM, aiming for an $\mathrm{HbA}_{1 \mathrm{c}}$ below 6\%, raised concerns when it reported increased CVD events in the intensive glucose lowering arm. The Action in Diabetes and Vascular Disease $\left(\right.$ ADVANCE) ${ }^{19}$ study and the Veterans Affairs Diabetes Trial (VADT) ${ }^{20}$ showed no benefit of intensive over standard glucose control on CVD rates, with no excess CVD events in the intensive arms.
Contentious meta-analysis data have linked one of the glucose lowering therapies (the thiazolidinedione, rosiglitazone) with an adverse cardiovascular event profile, ${ }^{21}$ and rosiglitazone is now not recommended in subjects with CVD. More recent retrospective data have raised similar concerns over elevated CVD events with sulphonylureas compared with other glucose lowering agents. $^{22}$

Thus tight control of blood glucose at the time of diagnosis is likely to be more beneficial than tightening control later when years of glucose elevation have contributed to accumulation of subclinical vascular disease. The choice of glucose lowering agent may also be an important factor in reducing cardiovascular events long term.

\section{Blood pressure}

Blood pressure (BP) lowering in people with T2DM independently reduces major cardiovascular events (Table 1). ${ }^{23}$ The NICE guideline CG66 recommends a target $\mathrm{BP}$ of $140 / 80 \mathrm{mmHg}$ (Table 2), though in patients with renal, ophthalmic or cerebrovascular damage a level of $130 / 80 \mathrm{mmHg}$ is suggested. In the presence of microalbuminuria, angiotensin-converting enzyme inhibitors (ACEI) or angiotensin II receptor blockers (ARB) are indicated regardless of the presence of hypertension. ${ }^{24}$ ACEIs should be the initial antihypertensive therapy in T2DM if lifestyle intervention does not result in BP lowering. In people of Afro-Caribbean descent an ACEI should be prescribed with a calcium-channel blocker (CCB) or thiazide diuretic. Most hypertensive people with T2DM are likely to require multiple agents to manage hypertension. After an ACEI/ARB, guidelines recommend the addition of CCBs, then a thiazide diuretic followed by betablockers, alpha-blockers or potassiumsparing diuretics.

\section{Lipids}

Total cholesterol and LDL lowering reduces major cardiovascular events in people with $\mathrm{T}_{2 \mathrm{DM}}{ }^{25}$ Lipid management

Table 1. Clinical studies in cardiovascular risk management of type 2 diabetes (T2DM).

\begin{tabular}{|c|c|}
\hline Study & Summary \\
\hline \multicolumn{2}{|l|}{ Glucose control } \\
\hline UKPDS $34^{15}$ & $\begin{array}{l}\text { Glucose lowering with metformin in obese patients with T2DM reduces macrovascular disease incidence } \\
(n=342)\end{array}$ \\
\hline UKPDS 10-year follow-up ${ }^{17}$ & $\begin{array}{l}\text { Reductions in cardiovascular events emergent in follow-up of original UKPDS glucose lowering studies } \\
\text { five years after cessation of trials }(n=3,277)\end{array}$ \\
\hline \multirow[t]{2}{*}{ ACCORD $^{18}$} & Intensive (aiming for $\mathrm{HbA}_{1 \mathrm{c}}<6.0 \%$ ) v standard glucose control \\
\hline & Study stopped early as increased mortality in intensive arm $(n=10,251)$ \\
\hline \multirow[t]{2}{*}{ ADVANCE $^{19}$} & Intensive glucose control $v$ standard glucose control $\left(\mathrm{HbA}_{1 \mathrm{c}} 6.5 \%\right.$ v $\left.7.3 \%\right)$ \\
\hline & No significant reduction in cardiovascular events or cardiovascular mortality in intensive arm $(n=11,140)$ \\
\hline \multirow[t]{2}{*}{ VADT 20} & Intensive $v$ standard glucose control $\left(\mathrm{HbA}_{1 \mathrm{c}} 8.4 \%\right.$ v $\left.6.9 \%\right)$ \\
\hline & No significant improvement in cardiovascular outcomes between groups $(n=1,791)$ \\
\hline \multicolumn{2}{|l|}{ Lipid management } \\
\hline $\begin{array}{l}\text { MRC/BHF Heart Protection } \\
\text { Study }{ }^{25}\end{array}$ & $\begin{array}{l}\text { Major cardiovascular events reduced by a quarter in people with diabetes randomised to simvastatin } 40 \mathrm{mg} \mathrm{v} \\
\text { placebo irrespective of baseline cholesterol level }(n=5,963)\end{array}$ \\
\hline \multicolumn{2}{|l|}{ Blood pressure management } \\
\hline UKPDS $38^{23}$ & $\begin{array}{l}\text { Major cardiovascular events reduced by a third in patients randomised to intensive } v \text { standard blood pressure } \\
\text { control }(n=1,148)\end{array}$ \\
\hline HOPE (MICRO-HOPE) ${ }^{24}$ & Cardiovascular events reduced in patients with diabetes randomised to ramipril $v$ placebo $(n=3,577)$ \\
\hline ALLHAT $^{26}$ & $\begin{array}{l}\text { Cardiovascular outcomes reduced by treatment with thiazide diuretic or ACEI/CCB in people with hypertension } \\
\text { and diabetes }(n=12,063)\end{array}$ \\
\hline
\end{tabular}

$\mathrm{ACEI}=$ angiotensin-converting enzyme inhibitor; $\mathrm{CCB}=$ calcium channel blocker. 
Table 2. Metabolic targets for type 2 diabetes mellitus (simplified adaptation from National Institute for Health and Clinical Excellence CG 66: for full guidance see Ref 12).

\begin{tabular}{lll} 
& Target & Pro \\
\hline $\mathrm{HbA}_{1 \mathrm{c}}$ & $<6.5 \%$ & If on mono- or dual therapy \\
& $<7.5 \%$ & If on triple therapy or insulin \\
Blood pressure & $<140 / 80 \mathrm{mmHg}$ & All hypertensive patients with diabetes \\
& $<130 / 80$ & Hypertensive patients with diabetes if eye, kidney or cerebrovascular damage \\
Lipids & Total cholesterol $<4 \mathrm{mmol} / \mathrm{I}$ & Treat with statin if $>40$ years of age and normal-to-high cardiovascular risk or \\
& Low-density lipoprotein $<2 \mathrm{mmol} / \mathrm{l}$ & $<40$ years of age with high cardiovascular risk \\
& & If $>40$ years with low-risk, assess using UKPDS risk engine
\end{tabular}

is central to the management of cardiovascular risk in all adults over 40 years of age with T2DM (Table 2). People with diabetes over 40 years of age at perceived low cardiovascular risk should have their risk assessed using the UKPDS risk engine. ${ }^{27}$ If cardiovascular risk is greater than $20 \%$ over 10 years, lipid-lowering therapy should be initiated. NICE CG66 recommends target levels of total cholesterol and LDL of $4 \mathrm{mmol} / \mathrm{l}$ and $2 \mathrm{mmol} / \mathrm{l}$, respectively. Initial therapy should be with $40 \mathrm{mg}$ of generic simvastatin, with the use of a more potent statin or ezetimibe, should target levels not be achieved.

NICE guidelines suggest that triglyceride levels over $4.5 \mathrm{mmol}$ should also be managed actively with a fibrate if lifestyle measures and optimisation of glucose control fail to control the hypertriglyceridaemia, though evidence that this impacts on CVD rates is limited.

\section{Antithrombotic therapy}

Current NICE guidelines advise lowdose aspirin (75 mg) for people with diabetes over 50 years of age with BP less than $145 / 75 \mathrm{mmHg}$ and for those below 50 years if significant cardiovascular risk factors are present. The risks and benefits of aspirin therapy as primary prevention should be considered for each individual, though in those with low CVD risk, aspirin may not be of benefit.

\section{Cardiovascular risk in type 1 diabetes}

Traditionally, management of hyperglycaemia in T1DM has focused on the reduction of microvascular complications. However, cardiovascular risk is markedly elevated in people with T1DM, the age-adjusted relative risk for CVD being greater for T1DM than T2DM. ${ }^{28}$ The complications of T1DM, for instance nephropathy, as well as hypertension and dyslipidaemia, result in elevated cardiovascular risk. As with T2DM, hyperglycaemia promotes atherogenesis by means of increased oxidative stress, endothelial dysfunction, inflammation and prothrombotic changes. Tight management of glucose control in T1DM has been shown in the Epidemiology of Diabetes Interventions and Complications (EDIC)/Diabetes and Complications Trial (DCCT) follow-up data to reduce vascular events many years later, even as intensive control wanes. ${ }^{29}$ Current advice recommends control of glucose levels with the avoidance of significant hypoglycaemia to reduce cardiovascular risk in T1DM.

People with T1DM are less well represented in the large cholesterol lowering and blood pressure management studies. However in the Heart Protection Study, ${ }^{25}$ there was a non-significant reduction in vascular events in a small subset of patients with T1DM. The study was underpowered to detect a benefit from a generic approach to cholesterol lowering in T1DM and further studies in this area are warranted. Management of blood pressure and proteinuria with ACEIs may also result in significant cardiovascular benefits. Smoking cessation and lifestyle modulation remain central to the management of cardiovascular risk in this group.

\section{Conclusions}

DM confers a high degree of cardiovascular risk brought about by multiplicative risk factors. Early, aggressive glucose lowering results in cardiovascular risk reduction in T2DM but this effect may not become apparent for many years. However, multiple risk factor modulation, including lifestyle interventions, BP lowering and lipid management together with glucose control results in significant and early reductions in CVD end-points. Evidence supports the benefit of glucose lowering for cardiovascular risk reduction in T1DM. Lipid lowering and BP management with ACEIs and other antihypertensive therapies may also be beneficial in the reduction of cardiovascular events in people with T1DM and elevated cardiovascular risk.

\section{References}

1 Kannel WB, McGee DL. Diabetes and glucose tolerance as risk factors for cardiovascular disease: the Framingham study. Diabetes Care 1979;2:120-6.

2 Stamler J, Vaccaro O, Neaton JD, Wentworth D. Diabetes, other risk factors, and 12-yr cardiovascular mortality for men screened in the Multiple Risk Factor Intervention Trial. Diabetes Care 1993;16:434-44.

3 Dorman JS, Laporte RE, Kuller LH et al. The Pittsburgh insulin-dependent diabetes mellitus (IDDM) morbidity and mortality study. Mortality results. Diabetes 1984;33:271-6.

4 Orchard TJ, Costacou T, Kretowski A, Nesto RW. Type 1 diabetes and coronary artery disease. Diabetes Care 2006;29:2528-38.

5 Yorkshire and Humber Public Health Observatory (YHPHO). PBS Phase 3 
Diabetes Population Prevalence Model, 1 April 2008. www.yhpho.org.uk/resource/ view.aspx?RID=81090. Accessed July 2010.

6 Wingard DL, Barrett-Connor E. Heart disease and diabetes. In: Harris MI, Cowie CC, Stern MP et al (eds). Diabetes in America, 2nd edn. Washington, DC: US Government Printing Office, 1995:429-48.

7 Faxon DP, Fuster V, Libby $\mathrm{P}$ et al. Atherosclerotic Vascular Diesease Conference: writing group III: pathophysiology. Circulation 2004;109:2617-25.

8 Fontbonne AM, Eschwege EM. Insulin and cardiovascular disease: Paris Prospective Study. Diabetes Care 1991;14:461-9.

9 Ludmer PL, Selwyn AP, Shook TL et al. Paradoxical vasoconstriction induced by acetylcholine in atherosclerotic coronary arteries. N Engl J Med 1986;315:1046-51.

10 Nathan DM, Lachin J, Cleary P et al; Diabetes Control and Complications Trial; Epidemiology of Diabetes Interventions and Complications Research Group. Intensive diabetes therapy and carotid intima-media thickness in type 1 diabetes mellitus. N Engl J Med 2003;348:2294-303.

11 Anderson KM, Wilson PW, Odell PM, Kannel WV. An updated coronary risk profile. A statement for health professionals. Circulation 1991;83:356-62.

12 National Institute for Health and Clinical Excellence. Type 2 diabetes; the management of type 2 diabetes. London: NICE, 2008.

13 Hippisley-Cox J, Coupland C, Vinogradova $\mathrm{Y}$ et al. Predicting cardiovascular risk in England and Wales: prospective derivation and validation of QRISK2. BMJ 2008;336:1475-82.

14 Wei M, Gaskill SP, Haffner SM, Stern MP. Effects of diabetes and level of glycaemia on all-cause and cardiovascular mortality. Diabetes Care 1998;21:1167-72.

15 UK Prospective Diabetes Study (UKPDS) Group. Effect of intensive blood-glucose control with metformin on complications in overweight patients with type 2 diabetes: UKPDS 34. Lancet 1998;352:854-65.

16 Control Group, Turnbull FM, Abraira C, Anderson RJ et al. Intensive glucose control and macrovascular outcomes in type 2 diabetes. Diabetologia 2009;52:2288-98.

17 Holman RR, Paul SK, Bethel MA, Matthews DR, Neil HA. 10-year follow-up of intensive glucose control in type 2 diabetes. N Engl J Med 2008;359:1577-89.

18 Gerstein HC, Miller ME, Byington RP et al; Action to Control Cardiovascular Risk in Diabetes Study Group,. Effects of intensive glucose lowering in type 2 diabetes. $N$ Engl J Med 2008;358:2545-59.

19 The ADVANCE Collaborative Group. Intensive blood glucose control and vascular outcomes in patients with type 2 diabetes. $N$ Engl J Med 2008;358:2560-72.

20 Duckworth W, Abraira C, Moritz T et al; VADT investigators. Glucose control and vascular complications in veterans with type 2 diabetes. $N$ Engl J Med 2009;360:129-39.

21 Richter B, Bandeira-Echtler E, Bergerhoff $\mathrm{K}$, Clar C, Ebrahim SH. Rosiglitazone for type 2 diabetes mellitus. Cochrane Database Syst Rev 2007; (3):CD006063.

22 Tzoulaki I, Molokhia M, Curcin V et al. Risk of cardiovascular disease and all cause mortality among patients with type 2 diabetes prescribed oral antidiabetes drugs: retrospective cohort study using UK general practice research database. BMJ 2009;339:b4731.

23 UK Prospective Diabetes Study Group. Tight blood pressure control and risk of macrovascular and microvascular complications in type 2 diabetes: UKPDS 38. BMJ 1998;317:703-13.

24 Heart Outcomes Prevention Evaluation Study Investigators. Effects of ramipril on cardiovascular and microvascular outcomes in people with diabetes mellitus: results of the HOPE study and MICROHOPE substudy. Lancet 2000;355:253-9.

25 Collins R, Armitage J, Parish S, Sleigh P, Peto R; Heart Protection Study Collaborative Group. MRC/BHF Heart Protection Study of cholesterol-lowering with simvastatin in 5963 people with diabetes: a randomised placebo-controlled trial. Lancet 2003;361:2005-16.

26 ALLHAT Officers and Coordinators for the ALLHAT Collaborative Research Group. The Antihypertensive and Lipid-Lowering Treatment to prevent Heart Attack Trial (ALLHAT-LLT). Major outcomes in highrisk hypertensive patients randomized to angiotensin-converting enzyme inhibitor or calcium channel blocker vs diuretic. JAMA 2002;288:2981-97.

27 University of Oxford, Diabetes Trials Unit Website: UKPDS Risk Engine. www.dtu.ox.ac.uk/riskengine/index.php. Accessed July 2010.

28 Libby P, Nathan DM, Abraham K et al. Report of the National Heart, Lung and Blood Institute-National Institute of Diabetes and Digestive and Kidney Disease Working Group on Cardiovascular Complications of Type 1 Diabetes Mellitus. Circulation 2005;111:3489-93.

29 Nathan DM, Cleary PA, Backlund JY et al; Diabetes Control and Complications Trial/Epidemiology of Diabetes Interventions and Complications (DCCT/EDIC) Study Research Group. Intensive diabetes treatment and cardiovascular disease in patients with type 1 diabetes. N Engl J Med 2005;353:2643-53.

\author{
Address for correspondence: \\ Dr AW Roberts, Ward B7, \\ University Hospital of Wales, \\ Heath Park, Cardiff CF14 4XW. \\ Email: aled.roberts2@wales.nhs.uk
}

